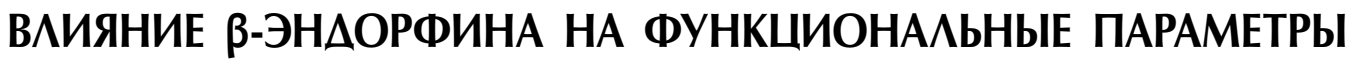 ИЗОАИРОВАННОГО СЕРАЦА И АИМФАТИЧЕСКИХ СОСУАОВ БЕАОЙ КРЫСЫ
}

\author{
О.В. Нечайкина, А.С. Ааптев, С.Г. Петунов, А.С. Радилов \\ ФГУП «Научно-исследовательский институт гигиены, профпатологии и экологии человека» \\ Федерального медико-биологического агентства, Ленинградская обл.
}

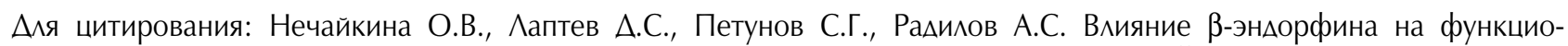
нальные параметры изолированного сердца и лимфратических сосудов белой крысы // Вестник Северо-Западного государственного медицинского университета им. И.И. Мечникова. - 2019. - Т. 11. - № 2. - C. 43-48. https://doi. org/10.17816/mechnikov201911243-48

Поступила: 15.01.2019

Одобрена: 17.04.2019

Принята: 10.06.2019

- Работа посвящена сравнению механизмов действия $\beta$-эндорфина в изолированных органах крысы (сердце и лимфатические сосуды). В ходе экспериментальных исследований установлено, что наиболее вероятной мишенью для $\beta$-эндорфина в изолированном сердце крысы являются $\delta$-опиоидные рецепторы, а в изолированных лимфатических сосудах крысы $-\mu$ - и $\delta$-опиоидные рецепторы. Ингибирующее действие $\beta$-эндорфина в сердечной мышце связано со стимуляцией АТФ-чувствительных калиевых каналов. В изолированных лимфатических сосудах эффект $\beta$-эндорфина реализуется посредством активации как потенциалзависимых, так и АТФ-чувствительных калиевых каналов.

- Ключевые слова: изолированное сердце; изолированные лимфатические сосуды; $\beta$-эндорфин; опиоидные рецепторы; опиоидные антагонисты; $\mathrm{K}^{+}$-каналы.

\section{THE EFFECT OF $\beta$-ENDORPHIN ON THE FUNCTIONAL PARAMETERS OF THE ISOLATED HEART AND LYMPHATIC VESSELS OF THE WHITE RAT}

\author{
O.V. Nechaykina, D.S. Laptev, S.G. Petunov, A.S. Radilov
}

Research Institute of Hygiene, Occupational Pathology and Human Ecology

of the Federal Medical and Biological Agency, Leningrad Region, Russia

For citation: Nechaykina OV, Laptev DS, Petunov SG, Radilov AS. The effect of $\beta$-endorphin on the functional parameters of the isolated heart and lymphatic vessels of the white rat. Herald of North-Western State Medical University named after I.I. Mechnikov. 2019;11(2):43-48. https://doi.org/10.17816/mechnikov201911243-48

Received: January 15, 2019

Revised: April 17, 2019

Accepted: June 10, 2019

- Purpose. The article is devoted to the comparison of the mechanisms of $\beta$-endorphin action in isolated rat heart and lymphatic vessels.

Materials and methods. The experiments were performed using the Langendorff System perfusion device (Panlab, Spain) and the multichannel wire myograph $620 \mathrm{M}$ (DMT). During the study, selective opioid receptor blockers, $\mathrm{K}^{+}$channel blockers were used.

Conclusion. In the course of experimental studies it was found that the most likely target for $\beta$-endorphin in an isolated rat heart are $\delta$-opioid receptors, in isolated lymphatic vessels of a rat $-\mu$ - and $\delta$-opioid receptors. The inhibitory effect of $\beta$-endorphin in the heart muscle is associated with stimulation of ATP-sensitive $\mathrm{K}^{+}$channels. In isolated lymphatic vessels, the effect of $\beta$-endorphin is actualized through the activation of both potential-dependent and ATP-sensitive $\mathrm{K}^{+}$channels.

- Keywords: isolated heart; isolated lymphatic vessels; $\beta$-endorphin; opioid receptors; opioid antagonists; $\mathrm{K}^{+}$channels.

\section{Введение}

Эндогенные агонисты опиоидных рецепторов (ОР), как составная часть опиоидергической системы организма, обладают широким спектром физиологической активности, обеспечивая существенный вклад в формирование адапта- ции организма к действию стрессорных факторов. Наиболее значимые эффекты, реализуемые при участии эндогенных опиатов, опосредованы модуляцией деятельности ноцицептивной, сердечно-сосудистой, дыхательной, эндокринной систем, психоэмоциональных процессов. 
Механизмы действия эндогенных ОР связаны со снижением уровня цАМФ, увеличением продукции оксида азота(II), активацией калиевых каналов, угнетением кальциевого тока.

В ряду перечисленных эффектов важнейшая роль агонистов ОР связана с повышением устойчивости миокарда к ишемическим - peперфузионным воздействиям. Установлено, что эндогенные опиаты имитируют феномен «ишемического прекондиционирования» [1]. Стимуляция ОР сопровождается гемодинамическими эффектами, приводящими к уменьшению сердечного выброса и, как следствие, системного артериального давления, ослаблению адренергических влияний на миокард [2]. На сарколемме кардиомиоцитов, эндотелии и гладкомышечных клетках сосудов экспрессируются различные типы ОР, что обусловливает различие эффектов их стимуляции в разных объектах сердечно-сосудистой системы [3-8].

Целью данного исследования являлась сравнительная характеристика действия $\beta$-эндорфина (эндогенного агониста $\mu$ - и $\delta$-ОР) на сократительную активность изолированного сердца и сегментов лимфатических сосудов (лимфангионов). Выбор объектов исследования был обусловлен сходством параметров их сократительной активности, а также определенной общностью регуляторных механизмов кардиомиоцитов и гладкомышечных клеток лимфатических сосудов [9-12].

\section{Материалы и методы}

Работы с животными выполняли с соблюдением правил биоэтики, утвержденных Европейской конвенцией о защите позвоноч- ных животных, используемых для экспериментальных и других целей. После эвтаназии, проведенной методом цервикальной дислокации, вскрывали грудную клетку и брюшную полость крысы. С использованием методики, описанной ранее [13], сердце извлекали из грудной клетки и фиксировали в перфузионной установке Langendorff System (PanLab). Кольцевые сегменты сосудов шириной 1,5-2 мм вырезали из переднего брыжеечного лимфатического протока и помещали в рабочую камеру миографа Multi Wire Myograph System DMT 610M [14]. В обоих экспериментах обеспечивали постоянную перфузию термостатируемым $\left(37,0 \pm 0,2^{\circ} \mathrm{C}\right)$ физиологическим раствором Кребса для позвоночных животных. Регистрировали следующие параметры: для сердца - пульсовое давление (ПД) и частоту сердечных сокращений (ЧСС); для сегментов лимфангионов - частоту и амплитуду фазных сокращений. Для адекватной оценки изменения сократительной активности под влиянием вазоактивных веществ использовали показатель минутной производительности, рассчитываемый с помощью программного обеспечения миографической аппаратуры (в частности, LabChart v.7) как площадь под кривой на записи одиночных сокращений мышечных органов (рис. 1, на примере лимфатических сосудов).

После окончания стабилизационного периода (30 мин) в перфузат добавляли $\beta$-эндорфин (Sigma Aldrich, США) в диапазоне концентраций $7 \cdot 10^{-13}-7 \cdot 10^{-7} \mathrm{M}$ для определения дозозависимости эффекта. Для изучения механизмов действия $\beta$-эндорфина использовали селективные антагонисты $\delta$ - и $\mu$-ОР - налтриндол и СТОР (Sigma Aldrich, США, в концентра-

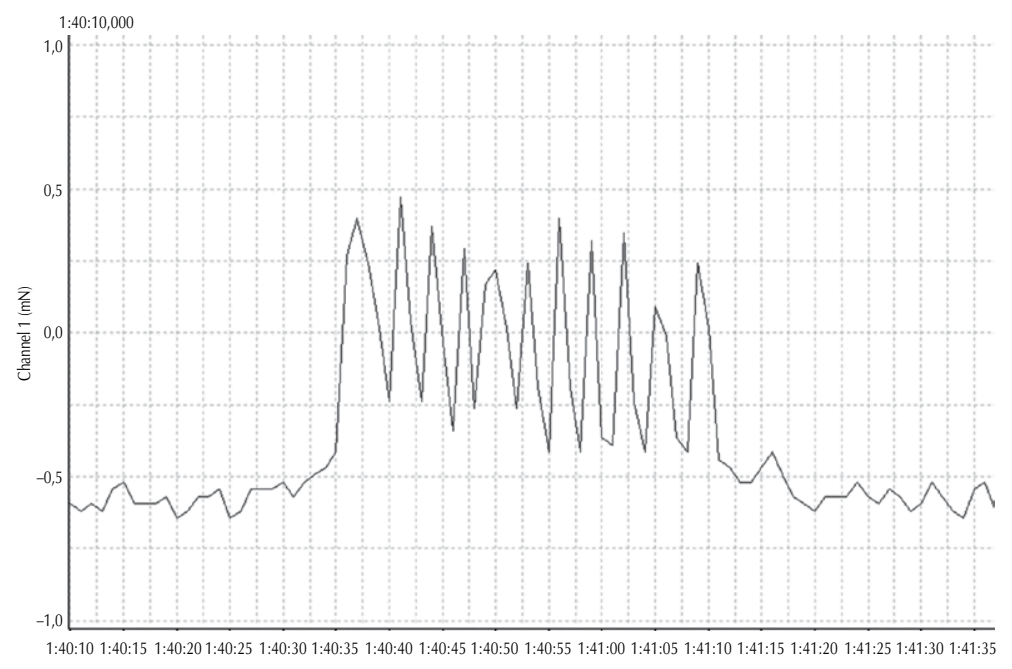

Рис. 1. Одиночное сокращение лимфангионов брыжейки крысы

Fig. 1. A single contraction of rat mesentery lymphangions 
Параметры сократительной активности изолированных органов под Аействием $\beta$-эндорфина по отношению к фоновым Аанным. Аанные представлены в относительных единицах $(M \pm S E)$

The parameters of the contractive activity of isolated organs under the action of $\beta$-endorphin in relation to the background data. The data are presented in relative units $(M \pm S E)$

\begin{tabular}{|c|c|c|c|c|c|c|}
\hline \multirow{2}{*}{$\begin{array}{c}\text { Концентрация } \\
\beta \text {-эндорфина, M }\end{array}$} & \multicolumn{2}{|c|}{ ЧСС/ЧС } & \multicolumn{2}{|c|}{ ПА/Ампхитуда } & \multicolumn{2}{|c|}{ Int/Производительность } \\
\hline & $\begin{array}{l}\text { Сердце } \\
(n=16)\end{array}$ & $\begin{array}{c}\Lambda C \\
(n=8)\end{array}$ & $\begin{array}{l}\text { Сердце } \\
(n=16)\end{array}$ & $\begin{array}{c}\Lambda C \\
(n=8)\end{array}$ & $\begin{array}{l}\text { Сердие } \\
(n=16)\end{array}$ & $\begin{array}{c}\Lambda C \\
(n=8)\end{array}$ \\
\hline $7 \cdot 10^{-13}$ & $0,99 \pm 0,03$ & $0,99 \pm 0,04$ & $0,91 \pm 0,03^{\star}$ & $1,01 \pm 0,03$ & $0,88 \pm 0,02^{*}$ & $0,90 \pm 0,05$ \\
\hline $7 \cdot 10^{-12}$ & $0,97 \pm 0,03$ & $0,89 \pm 0,07$ & $0,93 \pm 0,04$ & $1,04 \pm 0,04$ & $0,91 \pm 0,05$ & $0,83 \pm 0,07^{\star}$ \\
\hline $7 \cdot 10^{-11}$ & $0,99 \pm 0,01$ & $0,83 \pm 0,07$ & $0,99 \pm 0,02$ & $0,97 \pm 0,05$ & $0,94 \pm 0,02^{*}$ & $0,79 \pm 0,03^{*}$ \\
\hline $7 \cdot 10^{-10}$ & $0,98 \pm 0,02$ & $0,83 \pm 0,08$ & $0,96 \pm 0,03$ & $1,09 \pm 0,09$ & $0,92 \pm 0,02^{*}$ & $0,83 \pm 0,03^{\star}$ \\
\hline $7 \cdot 10^{-9}$ & $0,97 \pm 0,02$ & $0,78 \pm 0,1$ & $0,99 \pm 0,02$ & $1,06 \pm 0,08$ & $0,90 \pm 0,02^{*}$ & $0,81 \pm 0,06^{*}$ \\
\hline $7 \cdot 10^{-8}$ & $0,96 \pm 0,03$ & $0,75 \pm 0,13^{*}$ & $0,99 \pm 0,04$ & $1,03 \pm 0,09$ & $0,97 \pm 0,02$ & $0,78 \pm 0,07^{\star}$ \\
\hline $7 \cdot 10^{-7}$ & $0,98 \pm 0,02$ & $1,01 \pm 0,11$ & $0,96 \pm 0,03$ & $0,97 \pm 0,13$ & $0,96 \pm 0,02$ & $0,88 \pm 0,12$ \\
\hline
\end{tabular}

П р и ме ч а н и е. ПД - пульсовое давление; ЧСС - частота сердечных сокращений; ЛС - лимфатические сосуды. * статистически значимые различия по сравнению с фоновыми значениями $(p \leq 0,05)$.

ции $\left.1 \cdot 10^{-7} \mathrm{M}\right)$; блокатор потенциалчувствительных К ${ }^{+}$-каналов 4-аминопиридин (4-AP) (Sigma Aldrich, США, в концентрации $\left.1 \cdot 10^{-6} \mathrm{M}\right)$; блокатор АТФ-чувствительных калиевых каналов глибенкламид (Glb) (Sigma Aldrich, США, в концентрации $\left.1 \cdot 10^{-5} \mathrm{M}\right)$.

При анализе результатов оценивали динамику параметров работы сердца и лимфатических сосудов по сравнению с фоновыми значениями. Статистическую обработку проводили в программе GraphPad Prism 5.04. Данные сравнивали с применением $t$-критерия Стьюдента или T-критерия Вилкоксона для связанных выборок, для выявления межгрупповых различий использовали $U$-критерий Манна - Уитни.

\section{Результаты}

Частота и амплитуда фазной активности исследуемых изолированных объектов (сердца и лимфатических сосудов) различаются более чем на два порядка. В связи с этим при анализе влияния тестируемых препаратов использовали относительные единицы, характеризующие ди- намику параметров фазной активности. В табл. 1 приведены регистрируемые и расчетные показатели сократимости изолированных органов при использовании $\beta$-эндорфина по отношению к фону (фоновые значения приняты за 1).

Из представленных данных следует, что $\beta$-эндорфин оказывает более выраженное влияние на лимфатические сосуды и в концентрации, соответствующей и превышающей его эндогенный уровень [15], приводит к угнетению их фазной активности (по показателю минутной производительности) преимущественно за счет частоты сокращений, максимально на $25 \%$ по отношению к фону. $\beta$-Эндорфин в концентрации $7 \cdot 10^{-10} \mathrm{M}$, соответствующей его эндогенному уровню, вызывал субмаксимальное угнетение сократительной активности обоих объектов исследования, поэтому в последующих экспериментах пептид использовали в данной концентрации.

В экспериментах, проведенных с применением селективных антагонистов $\mu$ - и $\delta$-ОР, ингибирующее сократительную активность действие $\beta$-эндорфина не проявлялось. Напротив, на фоне СТОР увеличивались ЧС и минутная

\section{Таблица 2 / Table 2}

ВАияние $\beta$-эндорфина на показатели сократительной активности лимфатических сосудов крысы на фоне СТОР. $\triangle$ анные представлены в относительных еАиницах $(M \pm S E)$

Effect of $\beta$-endorphin on the contractive activity indices of the rat lymphatic vessels on the background of CTOP. The data are presented in relative units $(M \pm S E)$

\begin{tabular}{|l|c|c|c|}
\hline \multicolumn{1}{|c|}{ Показатели } & Частота сокращений & Ампмитуда & Производитемьность \\
\hline$\beta$-Эндорфин $(n=8)$ & $0,83 \pm 0,08$ & $1,09 \pm 0,09$ & $0,83 \pm 0,03^{*}$ \\
\hline СТОР $(n=13)$ & $0,96 \pm 0,05$ & $1,01 \pm 0,02$ & $0,96 \pm 0,03$ \\
\hline СТОР, $\beta$-эндорфин $(n=13)$ & $1,08 \pm 0,07$ & $0,99 \pm 0,02$ & $1,04 \pm 0,05$ \\
\hline
\end{tabular}

П р и м е ч а н и е. * статистически значимые различия по сравнению с фоновыми значениями $(p \leq 0,05)$. 


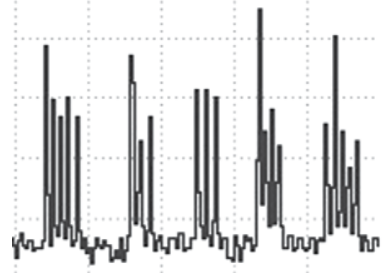

b

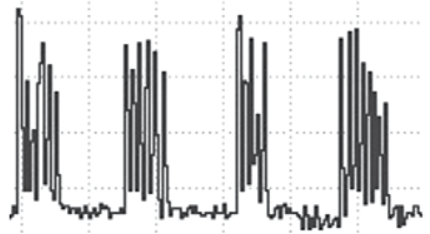

Рис. 2. Запись сократительной активности интактных лимфатических сосудов (фон) (a); запись сократительной активности лимфатических сосудов при воздействии $\beta$-эндорфина на фоне глибенкламида $(b)$

Fig. 2. Recording of the contractive activity of the intact lymphatic vessels (background) (a); recording of the contractile activity of the lymphatic vessels when exposed to $\beta$-endorphin on the background of Glb $(b)$

\section{Таблица 3 / Table 3}

Влияние $\beta$-эндорфина на показатели сократительной активности исследуемых объектов крысы на фоне блокаторов калиевых каналов. Аанные представлены в относительных единицах по отношению к фону $(M \pm S E)$

Effect of $\beta$-endorphin on the contractive activity of the rats under study against the background of $\mathrm{K}^{+}$channel blockers. The data are presented in relative units in relation to the background $(M \pm S E)$

\begin{tabular}{|c|c|c|c|c|c|c|}
\hline \multirow[b]{2}{*}{ Показатеки } & \multicolumn{2}{|c|}{ чСС/ЧС } & \multicolumn{2}{|c|}{ ПА/Ампкитуда } & \multicolumn{2}{|c|}{ Int/Производительность } \\
\hline & $\begin{array}{c}\text { сердие } \\
(n=10)\end{array}$ & $\begin{array}{c}\Lambda \mathrm{C} \\
(n=8 ; 8 ; 12)\end{array}$ & $\begin{array}{c}\text { сердие } \\
(n=10)\end{array}$ & $\begin{array}{c}\Lambda \mathrm{C} \\
(n=8 ; 8 ; 12)\end{array}$ & $\begin{array}{c}\text { сердце } \\
(n=10)\end{array}$ & $\begin{array}{c}\Lambda C \\
(n=8 ; 10 ; 10)\end{array}$ \\
\hline$\beta$-Эндорфин & $0,98 \pm 0,02$ & $0,83 \pm 0,08$ & $0,96 \pm 0,03$ & $1,09 \pm 0,09$ & $0,92 \pm 0,02^{\star}$ & $0,83 \pm 0,03^{\star}$ \\
\hline 4-AP & $0,94 \pm 0,02$ & $1,06 \pm 0,03$ & $1,07 \pm 0,03$ & $1,04 \pm 0,06$ & $1,01 \pm 0,03$ & $1,12 \pm 0,05$ \\
\hline 4-АР, $\beta$-эндорфин & $1,00 \pm 0,03$ & $0,95 \pm 0,06$ & $0,94 \pm 0,04$ & $1,05 \pm 0,04$ & $0,90 \pm 0,03$ & $1,10 \pm 0,06^{\#}$ \\
\hline Glb & $0,92 \pm 0,03$ & $1,05 \pm 0,04$ & $0,99 \pm 0,04$ & $0,96 \pm 0,03$ & $0,97 \pm 0,04$ & $1,09 \pm 0,06$ \\
\hline Glb, $\beta$-эндорфин & $0,90 \pm 0,03^{\#}$ & $0,98 \pm 0,04$ & $1,00 \pm 0,06$ & $0,97 \pm 0,08$ & $0,95 \pm 0,06$ & $1,29 \pm 0,10^{*, \#}$ \\
\hline
\end{tabular}

П р и ме ча н и е. ПД - пульсовое давление; ЧСС - частота сердечных сокращений; ЛС - лимфатические сосуды; Glb - глибенкламид; 4-AP - 4-аминопиридин. ${ }^{*}$ статистически значимые различия по сравнению с фоном $(p \leq 0,05)$; “ статистически значимые различия по сравнению с применением $\beta$-эндорфина $(p \leq 0,05)$; $n=8 ; 8 ; 12$ - количество наблюдений при отдельном применении $\beta$-эндорфина, в экспериментах с 4 -аминопиридином и глибенкламидом.

производительность лимфангионов на 12 и $8 \%$ соответственно (табл. 2).

На фоне применения блокаторов как потенциалзависимых, так и АТФ-чувствительных калиевых каналов снижение сократимости миокарда, вызванное действием $\beta$-эндорфина, практически не изменялось. В этих же условиях в лимфатических сосудах тормозный эффект $\beta$-эндорфина не проявлялся, а в случае с применением Glb минутная производительность лимфангионов увеличивалась, что было связано с увеличением продолжительности их одиночных сокращений (рис. 2). Результаты исследования приведены в табл. 3.

\section{Обсуждение}

Лимфатические сосуды в силу их морфофункциональных особенностей обладают свойствами, характерными как для сердечной жде всего вен. К настоящему времени хорошо известно, что механизмы, лежащие в основе сократительной активности крупных лимфатических протоков и сердечной мышцы, определяют цикличность процессов, приводящих к формированию переменного градиента давления и обеспечивающих нагнетательную функцию мышечных органов $[10,11]$. Несмотря на сходство процессов сокращения сердца и лимфангионов, имеются весьма существенные отличия регуляторных механизмов, обусловленных различающимися гидродинамическими условиями и особенностями рецепторного аппарата. Результаты исследования показали, что такие особенности характерны и для опиоидергической системы регуляции сократимости сердца и лимфатических сосудов.

Относительно гемодинамических эффектов опиоидных пептидов данные противоречивы, что обусловлено как различным дизайном исследования, так и морфофункциональными особен- 
ностями объектов сердечно-сосудистой системы. Большинство исследователей сходятся во мнении, что опиаты угнетают сердечную деятельность, и это подтверждено данными с использованием селективных лигандов $\delta$ - и к-опиоидных рецепторов [16-18]. Сосудистые же реакции обусловлены стимуляцией $\mu$-ОР на мембранах эндотелиальных клеток [19]. Вместе с тем известно, что эндогенные опиаты являются преимущественно неселективными лигандами ОР, что может служить причиной различной реактивности объектов сердечно-сосудистой системы.

В наших экспериментах выявлено отсутствие выраженного снижения сократимости миокарда в ответ на применение $\beta$-эндорфина на фоне селективного блокатора $\delta$-ОР налтриндола. Это хорошо согласуется с литературными данными [20], в соответствии с которыми при применении агониста $\delta$-OP DPDPE сократимость сердца снижалась, что было сопряжено с изменением фосфоинозитидного обмена, истощением запасов внутриклеточного кальция [21].

В изолированных лимфатических сосудах ингибирующее влияние $\beta$-эндорфина в присутствии блокатора $\delta$-ОР налтриндола также не проявлялось. Это свидетельствует в пользу того, что периферические $\delta$-ОР гладкомышечных клеток лимфатических сосудов опосредуют снижение сократительной функции лимфангионов, вызванное применением $\beta$-эндорфина. Отсутствие угнетающего сократимость лимфатических сосудов действия $\beta$-эндорфина было обнаружено и в присутствии блокатора $\mu$-ОР СТОР. Это указывает на то, что в лимфатических сосудах крысы ингибирующее действие $\beta$-эндорфина реализуется как через $\mu$-, так и через $\delta$-ОР.

Известно, что стимуляция $\delta$-ОР вызывает увеличение проницаемости калиевых каналов [22]. Согласно полученным в эксперименте данным блокатор потенциалзависимых калиевых каналов в изолированном сердце не приводит к отмене эффекта $\beta$-эндорфина, обусловливающего снижение минутной производительности миокарда. При этом выявлено более выраженное уменьшение инотропной функции левого желудочка (уменьшение ПД на $13 \%$ на фоне действия 4-АР), что может свидетельствовать о снижении кальциевого тока. На фоне Glb ингибирующий сократимость сердца эффект $\beta$-эндорфина отсутствовал, из чего следует, что влияние $\beta$-эндорфина в сердечной мышце в большей степени реализуется при участии АТФ-чувствительных калиевых каналов.

Влияние $\beta$-эндорфина на лимфатические сосуды реализуется, очевидно, посредством активации как потенциалзависимых, так и АТФ-чув- ствительных калиевых каналов, так как блокада этих каналов, вызванная применением 4-АР и Glb, снижала выраженность и даже устраняла тормозное влияние $\beta$-эндорфина на моторику лимфатических сосудов.

Кроме установленных различий механизмов влияния $\beta$-эндорфина, в наших экспериментах показано, что сократительная активность изолированного сердца и лимфатических сосудов изменяется при использовании $\beta$-эндорфина в концентрациях, в 10-100 раз более низких, чем его содержание в периферической крови в физиологических условиях $[15,23]$, что свидетельствует о высокой чувствительности методики ex vivo при исследовании действия изучаемого опиоидного пептида.

Таким образом, несмотря на определенную общность процессов, лежащих в основе сократимости и регуляции активности сердца и лимфангионов, существуют значительные различия в механизме действия $\beta$-эндорфина на данные объекты. Наиболее вероятной мишенью для $\beta$-эндорфина в изолированном сердце крысы являются $\delta$-ОР. Ингибирующее действие $\beta$-эндорфина связано со стимуляцией АТФ-чувствительных калиевых каналов. В отличие от сердца, в изолированных лимфатических сосудах крысы ингибирующее действие $\beta$-эндорфина реализуется посредством как $\mu$-, так и $\delta$-ОР. Ингибирующее действие $\beta$-эндорфина осуществляется в результате активации и потенциалзависимых, и АТФ-чувствительных калиевых каналов, при этом вклад АТФ-чувствительных калиевых каналов, вероятно, более значителен.

\section{Аитература}

1. Аасукова Т.В., Маслов А.Н., Горбунов А.С. О роли опиоидной системы миокарда в реализации кардиопротекторного эфффекта посткондиционирования // Российский фризиологический журнал им. И.М. Сеченова. - 2014. - Т. 100. - № 12 - С. 1391-1398. [Lasukova TV, Maslov LN, Gorbunov AS. On the role of opioid system of myocardium in the implementation of the cardioprotective effect of postconditioning. Russian Journal of Physiology. 2014;100(12):1391-1398. (In Russ.)]

2. Xiao RP, Pepe S, Spurgeon HA. Opioid peptide receptor stimulation reverses beta-adrenergic effects in rat heart cells. Am J Physiol. 1997;272:797-805. https://doi. org/10.1152/ajpheart.1997.272.2.H797.

3. Barron BA, Oakford LX, Gaugl JF, Caffrey JL. Methionineenkephalin-Arg-Phe immunoreactivity in heart tissue. Peptides. 1995;16:1221-1227. https://doi.org/10.1016/01969781(95)02012-L.

4. Barron BA. Opioid peptides and the heart. Cardiovasc Res. 1999;43:13-16. https://doi.org/10.1016/s00086363(99)00112-1. 
5. Маслов ^.Н., Аишманов Ю.Б., Гросс Г.Аж., Стефрано $А ж$. Феномен повышения устойчивости сердца к аритмогенному действию ишемии и реперфузии при активации перифрерических опиатных рецепторов // Вестник аритмологии. - 2002. - № 26. - С. 77-90. [Lishmanov YuB, Maslov LN,Gross G], Stefano GB. Fenomen povysheniya ustoichivosti serdtsa k aritmogennomu deistviyu ishemii i reperfuzii pri aktivatsii perifericheskikh opiatnykh retseptorov. Vestnik aritmologii. 2002;26:77-90. (In Russ.)]

6. Pugsley MK. The diverse molecular mechanisms responsible for the actions of opioids on the cardiovascular system. Pharmacol Ther. 2002;93(1):51-75. https://doi. org/10.1016/S0163-7258(02)00165-1.

7. Аишманов Ю.Б., Маслов А.Н. Опиатическая регуляция состояния центральной гемодинамики // Патологическая фризиология и экспериментальная терапия. 2003. - № 1. - C. 2-11. [Lishmanov YuB, Maslov LN. Opiaticheskaya regulyatsiya sostoyaniya tsentral'noi gemodinamiki. Patologicheskaya fiziologiya i eksperimental'naya terapiya. 2003;(1):2-11. (In Russ.)]

8. Saraiva J, Oliveira SM, Rocha-Sousa A, Leite-Moreira A. Opioid receptors and preconditioning of the heart. Rev Port Cardiol. 2004;23(10):1317-1333.

9. Quick CM, Venugopal AM, Gashev AA, et al. Intrinsic pump-conduit behavior of lymphangions. Am J Physiol Regul Integr Comp Physiol. 2007;292(4):R1510-R1518. https://doi.org/10.1152/ajpregu.00258.2006.

10. Berger DS, Li JK, Noordergraaf A. Differential effects of wave reflections and peripheral resistance on aortic blood pressure: a model-based study. Am J Physiol Heart Circ Physiol. 1994; 266:H1626-H1642. https://doi. org/10.1152/ajpheart.1994.266.4.h1626.

11. Li B, Silver I, Szalai JP, Johnston MG. Pressure-volume relationships in sheep mesenteric lymphatic vessels in situ: response to hypovolemia. Microvasc Res. 1998;56(2):127-138. https://doi.org/10.1006/mvre.1998.2089.

12. McHale NG, Roddie IC. The effect of transmural pressure on pumping activity in isolated bovine lymphatic vessels. J Physiol. 1976;261(2):255-269. https://doi.org/10.1113/ jphysiol.1976.sp 011557.

13. Ааптев А.С., Петунов С.Г., Бобков А.В., и др. Влияние $\beta$-эндорфина на фрункциональную активность изолированного сердца крысы // Российский физиомогический журна^ им. И.М. Сеченова. - 2016. T. 102. - № 11 - C. 1343-1351. [Laptev DS, Petunov SG, Bobkov DV, et al. Rembovskiy. Influence of $\beta$-endorphin on functional activity of isolated rat heart. Russian Journal of Physiology. 2016;102(11):1343-1351. (In Russ.)]

14. Нечайкина О.В., Петунов С.Г., Радилов А.С. Влияние $\beta$-эндорфина на сократительную активность изолированных мимфратических сосудов крысы // Регионарное кровообращение и микроциркуляция. - 2013. T. 12. - № 3. - C. 64-70. [Nechaykina OV, Petunov SG, Radilov AS. Effect of $\beta$-endorphin on contractile activity of isolated rat lymph vessels. Regional Blood Circulation and Microcirculation. 2013;12(3):64-70. (In Russ.)]

15. Брук Т.М., Аифрке М.В. Аинамика $\beta$-эндорфина в крови спортсменов различной квалифиикации в условиях нагрузки умеренной интенсивности на фоне низкоинтенсивного мазерного воздействия // Курский научно-практический вестник «Человек и его зАоровье». 2009. - № 2. - C. 5-10. [Brook TM, Lifke MV. Dynamics of beta-endorphin in the blood of athletes of various qualifications in the conditions of mild load exposed by low intensive laser. Kursk Scientific and Practical Bulletin "Man and His Health". 2009;(2):5-10. (In Russ.)]

16. Mantelli L, Corti V, Bini R, Ledda F. Role of opioid peptides in the peripheral regulation of cardiovascular function. Cardiologia. 1987;32(8):691-4. (In Italian).

17. Vargish T, Beamer KC. Delta and Mu receptor agonists correlate with greater depression of cardiac function than morphine sulfate in perfused rat hearts. Circ Shock. 1989;27(3):245-51.

18. Pugsley MK, Penz WP, Walker MJ, Wong TM. Cardiovascular actions of the K-agonist, $\mathrm{U}-50,488 \mathrm{H}$, in the absence and presence of opioid receptor blockade. Br J Pharmacol. 1992;105(3):521-526. https://doi. org/10.1111/j.1476-5381.1992.tb09012.x.

19. Stefano GB, Hartman A, Bilfinger TV, et al. Presence of the mu3 opiate receptor in endothelial cells. Coupling to nitric oxide production and vasodilation. J Biol Chem. 1995;270(51):30290-30293. https://doi. org/10.1074/jbc.270.51.30290.

20. Fu LW, Longhurst JC. Functional role of peripheral opioid receptors in the regulation of cardiac spinal afferent nerve activity during myocardial ischemia. Am J Physiol Heart Circ Physiol. 2013;305(1):H76-85. https://doi. org/10.1152/ajpheart.00091.2013.

21. Treskatsch S, Feldheiser A, Shaqura M, et al. Cellular localization and adaptive changes of the cardiac delta opioid receptor system in an experimental model of heart failure in rats. Heart Vessels. 2016;31(2):241-50. https:// doi.org/10.1007/s00380-014-0620-6.

22. Tanaka K, Kersten JR, Riess ML. Opioid-induced cardioprotection. Curr Pharm Des. 2014;20(36):5696-5705. https://doi.org/10.2174/1381612820666140204120311.

23. Первомайский Э.Б., Кузьминов В.Н. Аинамика содержания $\beta$-эндорфина, мет- и мей-энкефралина в плазме больных опийной наркоманией в процессе купирования абстинентного синарома // Биологически активные вещества и регуляция фрункций мозга: Сборник научных трудов. - Харьков, 1990. - С. 22-24. [Pervomaiskii EB, Kuz'minov VN. Dinamika soderzhaniya $\beta$-endorfina, met- i lei-enkefalina v plazme bol'nykh opiinoi narkomaniei $v$ protsesse kupirovaniya abstinentnogo sindroma. In: Biologicheski aktivnye veshchestva i regulyatsiya funktsii mozga: Sbornik nauchnykh trudov. Khar'kov; 1990. P. 22-24. (In Russ.)]

- Адрес автора для переписки (Information about the author) Ольга Валерьевна Нечайкина / Olga Nechaykina

Тел. / Tel.: +7(911)1500951 